\title{
Oral Tranexamic Acid in Hip and Knee Arthroplasty: A Prospective Cohort Study
}

\author{
Stephen McGrath, Piers Yates, Gareth Prosser \\ Department of Orthopaedic Surgery, Fremantle Hospital, Fremantle, Australia \\ Email: stephenmcgrath@icloud.com
}

Received 3 June 2014; revised 19 July 2014; accepted 1 August 2014

Copyright (C) 2014 by authors and Scientific Research Publishing Inc.

This work is licensed under the Creative Commons Attribution International License (CC BY). http://creativecommons.org/licenses/by/4.0/

(c) (i) Open Access

\begin{abstract}
Intravenous Tranexamic acid has been shown to decrease blood transfusion requirements in surgery. Little evidence exists regarding the much cheaper oral form. The objective of this cohort study was to evaluate whether oral tranexamic acid administration in patients undergoing elective hip and knee replacement surgery resulted in decreased transfusion requirements. Methods: We assessed the transfusion requirements of 332 patients following unilateral total hip or knee arthroplasty, with the first 140 receiving no tranexamic acid and the next 192 given $1 \mathrm{~g}$ oral tranexamic acid one hour prior to and a further $1 \mathrm{~g} 4$ hours post joint arthroplasty. Haemoglobin before and after surgery, the number of units transfused post-operatively and the incidence of deep vein thrombosis or pulmonary embolism were recorded. Results: In the first group, there were 22 instances of transfusion (15.7\%) and a mean haemoglobin drop of $32.2 \mathrm{~g} / \mathrm{L}$, while the second (tranexamic acid) group had just 12 patients transfused $(6.3 \%)$ and a mean haemoglobin drop of $24.6 \mathrm{~g} / \mathrm{L}$ (both significantly less, $p<0.01$ ). There was no significant difference in deep vein thrombosis or pulmonary embolism rates between groups. Conclusions: This is the first prospective study to analyze the outcome of oral tranexamic acid administration in hip and knee replacement. We conclude that oral tranexamic acid administration is a safe and effective means to decrease transfusion requirements in joint arthroplasty and is a much cheaper alternative to intravenous preparations of tranexamic acid.
\end{abstract}

\section{Keywords}

Tranexamic Acid, Blood Loss, Surgical, Blood Conservation Strategy, Total Hip Replacement, Total Knee Replacement

\section{Introduction}

Hip and knee replacement surgery results in significant blood loss, which has traditionally been dealt with by 
Allogenic Blood Transfusion (ABT). Recently, Patient Blood Management (PBM) strategies have been developed to minimize the use of this increasingly scarce, and expensive resource [1]-[3]. One such strategy involves the administration of the anti-fibrinolytic, Tranexamic Acid (TXA) and this has clearly been shown to significantly reduce transfusion rates in both cardiac [4], trauma [5] and orthopaedic surgery [6]-[13].

TXA is a synthetic lysine analogue developed in Japan in the late 1950s and previously used to treat menorrhagia. It inhibits fibrinolysis by blocking the lysine binding sites on plasminogen, thereby inhibiting plasmin formation [4]. The vast majority of the studies investigating the efficacy and outcomes of TXA in joint replacement have involved various permutations in timing of administration of intravenous (IV) TXA. Limited evidence exists regarding oral TXA in orthopaedic surgery.

Our institution has elected to use oral TXA on the basis of the practice of one author since 2006 at another site. The purpose of this study was to confirm whether administration of oral TXA could significantly reduce transfusion requirements in both hip and knee replacement surgery. We hypothesized that the oral form of TXA given $1 \mathrm{~g}$ before and a further $1 \mathrm{~g} 4$ hours after surgery would decrease the transfusion rates with no increase in adverse outcomes.

\section{Patients and Method}

\subsection{Participants}

The initial control group of 140 patients was comprised of the last 20 consecutive primary hip or knee arthroplasty patients per surgeon leading up to September 2010 at the Fremantle Hospital and Health Service (including Kaleeya Hospital), Western Australia. The subsequent group of 192 primary hip or knee arthroplasty patients was again comprised of consecutive joint replacements per surgeon, around 27 per surgeon, up until June 2012 after the system-wide introduction of the oral tranexamic acid protocol. There were no exclusion criteria, all patients presenting for elective primary joint replacement (hip and knee) were included in the first group in a consecutive fashion prior to the introduction of TXA within the hospital system. The second group had to follow on chronologically from the first, allowing for a time interval in which implementation of TXA was established, and were similarly grouped as consecutive elective primary joint replacement patients per surgeon with no exclusions. The characteristics of each group are summarized in Table 1 . The 2 groups were comparable in age, pre-operative haemoglobin concentration and distribution of hip and knee replacement surgery (Table 1).

\subsection{Procedure}

Prescription of $1 \mathrm{~g}$ oral tranexamic acid (Cyklokapron, Pfizer) to be given at $1 \mathrm{hr}$ prior to and $4 \mathrm{hr}$ post surgery was instituted at the pre-admission clinic for all patients in the second arm of the study. Any previous Aspirin therapy was withheld for 5 days prior to surgery and likewise Clopidogrel withheld 7 days prior to surgery. All patients were prepped and draped in a standard fashion with tourniquet use for the TKR patients. Enoxaparin (Clexane, Sanofi-Aventis) $40 \mathrm{mg}$ subcutaneous was administered no earlier than 6 hours post op and patients were typically discharged on a non-steroidal anti-inflammatory and aspirin for 4 weeks. Immediate pre-operative and the lowest post-operative haemoglobin concentrations were recorded, along with incidence of post-operative blood transfusion and the number of units received per patient. These data were extracted from the hospital computer system. For the second group a medical record review was undertaken to record the timing of TXA administration along with concurrent administration of anticoagulant therapy, deep vein thrombosis (DVT),

Table 1. Pre-operative comparison of groups.

\begin{tabular}{ccc}
\hline Characteristic & \multicolumn{2}{c}{ Groups } \\
\cline { 2 - 3 } Mean age (years) & Control Group (n=140) & Tranexamic Acid Group (n = 192) \\
\hline Mean pre-op Haemoglobin (g/l) (range) & 67.7 & $137.6(80$ to 179$)$ \\
Number of TKR & $139.4(100$ to 183) & $112(58)$ \\
Number of THR & $71(51)$ & $80(42)$ \\
\hline
\end{tabular}

${ }^{\mathrm{a}}$ Total Knee Replacement; ${ }^{\mathrm{b}}$ Total Hip Replacement. 
Pulmonary Embolus (PE), or any other complications at the 3-month outpatient clinic follow-up.

\subsection{Statistical Analysis}

An unpaired t-test comparison was made to analyze the haemoglobin drop between groups. A chi-squared test was utilized to compare the rates of transfusion as well as instances of DVT and PE.

\section{Results}

\subsection{Transfusion Requirements}

The mean $\mathrm{Hb}$ drop for the pre-TXA control group was $32.2 \mathrm{~g} / \mathrm{L}$ and significantly less $(\mathrm{p}<0.0001)$ for the TXA group at $24.6 \mathrm{~g} / \mathrm{L}$. The number of patients transfused was lower in the TXA group (12 patients, 6.3\%) versus the control group (22 patients, 15.7\%) as seen in Table 2. This difference was significant ( $p=0.005)$. Out of the 22 and 12 patients transfused for the control and TXA groups respectively, 41 units were transfused to the control group and 20 to the TXA group.

\subsection{Follow-Up \& Complications}

The mean follow-up was 133 days. In the TXA group, there was one documented non-ST elevation Myocardial Infarction (NSTEMI), one DVT and three instances of PE confirmed by Computed Tomography Pulmonary Angiogram (CTPA). None of the transfused patients had been on anticoagulant medication prior to transfusion. In the control group, there was one incidence of DVT recorded. There was not a significant difference between groups in DVT or PE rates (p 0.822 and 0.137 respectively) as represented in Table 3. It should also be noted that eight of the 192 patients in the TXA group had previously had either a DVT or PE documented in their past medical history and none of the eight suffered a further DVT/PE in this study. Three patients went on to require further surgery for peri-prosthetic fractures after a fall or dislocation, 2 patients required washout for infection, 3 had manipulation for stiffness and there were 2 instances of wound cellulitis.

\section{Discussion}

The results of our study suggest that administration of oral tranexamic acid before and after joint replacement surgery is effective in decreasing haemoglobin drop, and blood transfusion rates with no significant increase in thrombotic complications. This is the first prospective study to analyze the outcome of oral tranexamic acid administration in hip and knee replacement.

High quality data including a Cochrane review [4] and meta-analysis [14] have confirmed the general efficacy

Table 2. Post-operative results.

\begin{tabular}{|c|c|c|c|}
\hline \multirow{2}{*}{ Characteristic } & \multicolumn{3}{|c|}{ Groups } \\
\hline & Control $(n=140)$ & Tranexamic Acid (n = 192) & p-Value \\
\hline Mean pre-op Haemoglobin (g/l) (range) & 139.4 (100 to 183$)$ & 137.6 (80 to 179$)$ & \\
\hline Mean post-op Haemoglobin (g/l) (range) & 107.3 (60 to 158$)$ & 113.0 (77 to 154$)$ & \\
\hline Mean Haemoglobin drop (g/l) & 32.2 & 24.6 & $<0.0001^{*}$ \\
\hline Number of patients transfused (\%) & $22(15.7)$ & $12(6.3)$ & $0.005^{*}$ \\
\hline Number of units transfused & 41 & 20 & \\
\hline
\end{tabular}

${ }^{*}$ p-value statistically significant.

Table 3. Thromboembolic complications.

\begin{tabular}{cccc}
\hline Characteristic & & Groups & \\
\cline { 2 - 4 } & Control $(\mathrm{n}=140)$ & Tranexamic Acid (n = 192) & $\mathrm{p}$-Value \\
\hline Number of patients diagnosed with DVT & 1 & 1 & 0.822 \\
Number of patients diagnosed with PE & 0 & 3 & 0.137 \\
\hline
\end{tabular}


of IV TXA in reducing ABT in surgery. Within the orthopaedic literature a meta-analysis looking at TXA in total hip arthroplasty confirmed the same with no difference in DVT/PE or complication rates but notably excluded oral TXA usage [6]. Similarly another systematic review of 19 randomized controlled trials of TXA in total knee replacement (TKR) showed reduced blood loss, transfusion rate and no increase in complications [15]. This review did include one oral TXA study by Zohar et al. [16] from 2004 involving 80 TKR patients divided into four groups of 20 patients. The three treatment groups were either given IV TXA, oral TXA or a combination both pre- and post-operatively. The rates of transfusion were significantly higher in the control group compared with the treatment arms and no significant difference was observed between the three TXA groups. The authors therefore concluded that despite different doses between groups, oral TXA by virtue of its simplicity in administration was more advantageous. A recently published, large retrospective analysis of 3000 joint replacement patients in the United Kingdom looked back at the outcomes of oral TXA administration over two short time periods in which a national shortage limited the IV supply [17]. They concluded that oral TXA (25 mg/kg to a maximum of $2 \mathrm{~g}$ given 2 hours prior) showed a similar safety profile to IV (15 mg/kg to a maximum of 1.2 g given at induction), and found, significantly, the odds ratio for receiving a transfusion higher in the IV group $(n=2698)$ than the oral $(n=302)$.

Many studies [11]-[13] have looked at the timing of TXA administration in the intravenous form with little or no difference between groups other than the difference seen between treatment and control (with no TXA given). Our simple regimen was to give $1 \mathrm{~g} 1$ hour prior and a further $1 \mathrm{~g} 4$ hours post-replacement surgery. We found no significant difference in rates of symptomatic venous thromboembolism than expected with one DVT and 3 instances of PE in the TXA group and one instance of DVT in the control group. This reflects previous studies that found no increase in thromboembolic complications with TXA use [17]-[20].

In May 2010, the World Health Organisation adopted the three pillars of patient blood management (PBM) [21]. The second pillar of patient blood management concerns strategies to minimize blood loss. Prior to this study in Western Australia, orthopaedic surgery accounted for 17\% of all transfusions (2008 to 2009) [22], with cost estimated at around \$875 per transfused unit in 2010 [23]. Our findings demonstrated a significant decrease in haemoglobin drop with oral tranexamic acid therapy and this led to a decreased rate of transfusion. Certainly this has direct implications in not only blood product conservation but also cost-saving from decreased blood product utilization and the relatively cheaper cost of oral tranexamic acid administration. At our institution a $1 \mathrm{~g}$ intravenous preparation of tranexamic acid cost $\$ 60.17$, whereas the equivalent oral dose cost only 0.82 cents (\$40.76 for $100 \times 500 \mathrm{mg}$ tablets), representing an over 70 -fold saving with oral TXA. The present study therefore highlights one simple and effective means of decreasing the demand and cost burden of transfusion, whilst complying with international recommendations.

\section{Limitations}

Western Australia has been at the forefront of PBM and has implemented a health-system-wide program since 2008 [21]. The current study involves just one component of the PBM system, however it also occurs at a time where the context is rapidly changing and the results have to be interpreted in the light of this. This study is not a randomized controlled trial where the subjects can be isolated from other good strategies that are occurring at a State-wide level. One such example relates to the first pillar of PBM which aims to optimize red cell mass; all patients presenting for elective joint replacement within the present institution will be screened for anaemia and pre-operatively optimized with treatment of underlying disorders like iron deficiency. One strategy therefore to improve our study would be to conduct a large randomized controlled trial comparing oral and IV TXA administration and attempt to measure all other variables within the PBM context such as concomitant iron administration and anticoagulation.

\section{Conclusion}

Our data suggest that oral TXA administration in the context of a PBM program decreases transfusion requirement without increased complications. This has implications for clinical practice, as oral TXA is simpler and significantly cheaper to administer.

\section{References}

[1] Isbister, J.P., Shander, A., Spahn, D.R., Erhard, J., Farmer, S.L. and Hofmann, A. (2011) Adverse Blood Transfusion 
Outcomes: Establishing Causation. Transfusion Medicine Reviews, 25, 89-101. http://dx.doi.org/10.1016/j.tmrv.2010.11.001

[2] Spahn, D.R. and Goodnough, L.T. (2013) Alternatives to Blood Transfusion. Lancet, 381, 1855-1865.

[3] Hofmann, A., Farmer, S.L. and Shander, A. (2011) Five Drivers Shifting the Paradigm from Product-Focused Transfusion Practice to Patient Blood Management. Oncologist, 16, 3-11.

[4] Henry, D.A., Carless, P.A., Moxey, A.J., O’Connell, D., Stokes, B.J., Fergusson, D.A. and Ker, K. (2011) Anti-Fibrinolytic Use for Minimising Perioperative Allogeneic Blood Transfusion. Cochrane Database of Systematic Reviews, Article ID: CD001886.

[5] Collaborators C-2T (2010) Effects of Tranexamic Acid on Death, Vascular Occlusive Events, and Blood Transfusion in Trauma Patients with Significant Haemorrhage (CRASH-2): A Randomised, Placebo-Controlled Trial. Lancet, 376, 23-32.

[6] Sukeik, M., Alshryda, S., Haddad, F.S. and Mason, J.M. (2011) Systematic Review and Meta-Analysis of the Use of Tranexamic Acid in Total Hip Replacement. Journal of Bone and Joint Surgery (British Volume), 93, 39-46. http://dx.doi.org/10.1302/0301-620X.93B1.24984

[7] Orpen, N.M., Little, C., Walker, G. and Crawfurd, E.J.P. (2006) Tranexamic Acid Reduces Early Post-Operative Blood Loss after Total Knee Arthroplasty: A Prospective Randomised Controlled Trial of 29 Patients. Knee, 13, 106-110. http://dx.doi.org/10.1016/j.knee.2005.11.001

[8] Zhou, X.-D., Tao, L.-J., Li, J. and Wu, L.-D. (2013) Do We Really Need Tranexamic Acid in Total Hip Arthroplasty? A Meta-Analysis of Nineteen Randomized Controlled Trials. Archives of Orthopaedic and Trauma Surgery, 133, 1017-1027. http://dx.doi.org/10.1007/s00402-013-1761-2

[9] Phillips, S.J., Chavan, R., Porter, M.L., Kay, P.R., Hodgkinson, J.P., Purbach, B., et al. (2006) Does Salvage and Tranexamic Acid Reduce the Need for Blood Transfusion in Revision Hip Surgery? Journal of Bone and Joint Surgery (British Volume), 88, 1141-1142. http://dx.doi.org/10.1302/0301-620X.88B9.17605

[10] Charoencholvanich, K. and Siriwattanasakul, P. (2011) Tranexamic Acid Reduces Blood Loss and Blood Transfusion after TKA: A Prospective Randomized Controlled Trial. Clinical Orthopaedics and Related Research, 469, $2874-2880$. http://dx.doi.org/10.1007/s11999-011-1874-2

[11] Lin, P.-C., Hsu, C.-H., Huang, C.-C., Chen, W.-S. and Wang, J.-W. (2012) The Blood-Saving Effect of Tranexamic Acid in Minimally Invasive Total Knee Replacement: Is an Additional Pre-Operative Injection Effective? Journal of Bone and Joint Surgery (British Volume), 94, 932-936. http://dx.doi.org/10.1302/0301-620X.94B7.28386

[12] Imai, N., Dohmae, Y., Suda, K., Miyasaka, D., Ito, T. and Endo, N. (2012) Tranexamic Acid for Reduction of Blood Loss during Total Hip Arthroplasty. The Journal of Arthroplasty, 27, 1838-1843. http://dx.doi.org/10.1016/j.arth.2012.04.024

[13] Maniar, R.N., Kumar, G., Singhi, T., Nayak, R.M. and Maniar, P.R. (2012) Most Effective Regimen of Tranexamic Acid in Knee Arthroplasty: A Prospective Randomized Controlled Study in 240 Patients. Clinical Orthopaedics and Related Research, 470, 2605-2612. http://dx.doi.org/10.1007/s11999-012-2310-y

[14] Ker, K., Edwards, P., Perel, P., Shakur, H. and Roberts, I. (2012) Effect of Tranexamic Acid on Surgical Bleeding: Systematic Review and Cumulative Meta-Analysis. BMJ, 344, e3054. http://dx.doi.org/10.1136/bmj.e3054

[15] Alshryda, S., Sarda, P., Sukeik, M., Nargol, A., Blenkinsopp, J. and Mason, J.M. (2011) Tranexamic Acid in Total Knee Replacement: A Systematic Review and Meta-Analysis. Journal of Bone and Joint Surgery (British Volume), 93, 1577-1585. http://dx.doi.org/10.1302/0301-620X.93B12.26989

[16] Zohar, E., Ellis, M., Ifrach, N., Stern, A., Sapir, O. and Fredman, B. (2004) The Postoperative Blood-Sparing Efficacy of Oral versus Intravenous Tranexamic Acid after Total Knee Replacement. Anesthesia Analgesia, 99, 1679-1683. http://dx.doi.org/10.1213/01.ANE.0000136770.75805.19

[17] Irwin, A., Khan, S.K., Jameson, S.S., Tate, R.C., Copeland, C. and Reed, M.R. (2013) Oral versus Intravenous Tranexamic Acid in Enhanced-Recovery Primary Total Hip and Knee Replacement: Results of 3000 Procedures. Journal of Bone and Joint Surgery (British Volume), 95, 1556-1561. http://dx.doi.org/10.1302/0301-620X.95B11.31055

[18] Ho, K.M. and Ismail, H. (2003) Use of Intravenous Tranexamic Acid to Reduce Allogeneic Blood Transfusion in Total Hip and Knee Arthroplasty: A Meta-Analysis. Anaesthesia and Intensive Care Journal, 31, 529-537.

[19] Gillette, B.P., DeSimone, L.J., Trousdale, R.T., Pagnano, M.W. and Sierra, R.J. (2012) Low Risk of Thromboembolic Complications with Tranexamic Acid after Primary Total Hip and Knee Arthroplasty. Clinical Orthopaedics and Related Research, 471, 150-154. http://dx.doi.org/10.1007/s11999-012-2488-z

[20] Yang, Z.-G., Chen, W.-P. and Wu, L.-D. (2012) Effectiveness and Safety of Tranexamic Acid in Reducing Blood Loss in Total Knee Arthroplasty: A Meta-Analysis. The Journal of Bone and Joint Surgery (American Volume), 94, 11531159. http://dx.doi.org/10.2106/JBJS.K.00873 
[21] Farmer, S.L., Towler, S.C., Leahy, M.F. and Hofmann, A. (2013) Drivers for Change: Western Australia Patient Blood Management Program (WA PBMP), World Health Assembly (WHA) and Advisory Committee on Blood Safety and Availability (ACBSA). Best Practice Research Clinical Anaesthesiology, 27, 43-58. http://dx.doi.org/10.1016/j.bpa.2012.12.007

[22] Mukhtar, S.A., Leahy, M.F., Trentino, K., Koay, A., Semmens, J.B., Tovey, J., Jewlachow, J., et al. (2013) Effectiveness of a Patient Blood Management Data System in Monitoring Blood Use in Western Australia. Anaesthesia and Intensive Care, 41, 207-215.

[23] Leahy, M.F. and Mukhtar, S.A. (2012) From Blood Transfusion to Patient Blood Management: A New Paradigm for Patient Care and Cost Assessment of Blood Transfusion Practice. Internal Medicine, 42, 332-338.

http://dx.doi.org/10.1111/j.1445-5994.2012.02717.x 
Scientific Research Publishing (SCIRP) is one of the largest Open Access journal publishers. It is currently publishing more than 200 open access, online, peer-reviewed journals covering a wide range of academic disciplines. SCIRP serves the worldwide academic communities and contributes to the progress and application of science with its publication.

Other selected journals from SCIRP are listed as below. Submit your manuscript to us via either submit@scirp.org or Online Submission Portal.
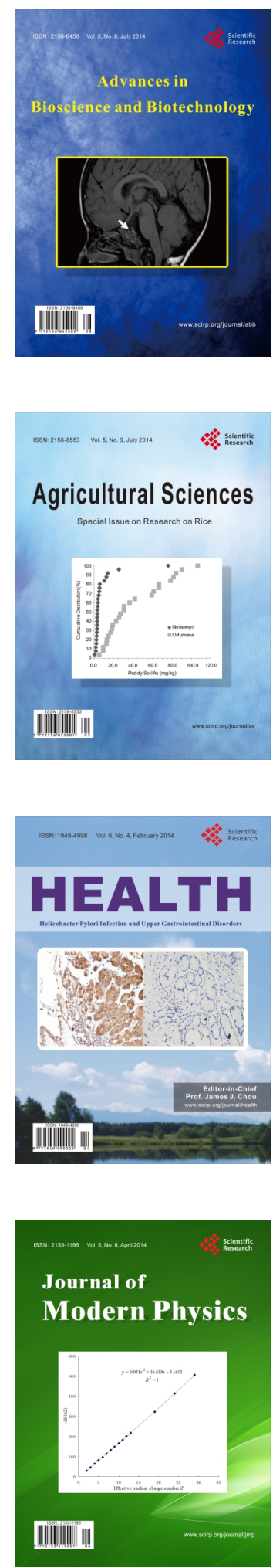
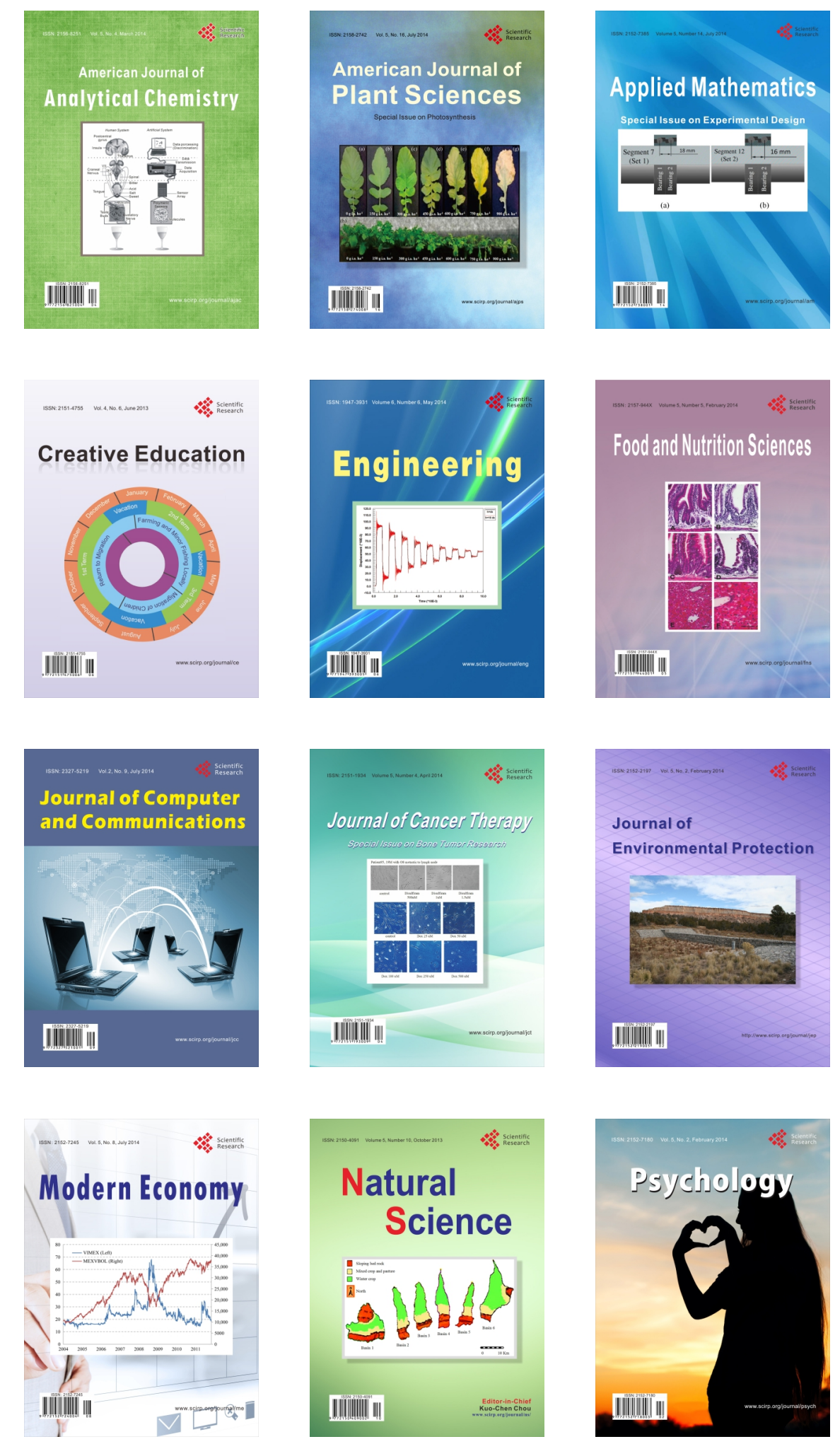